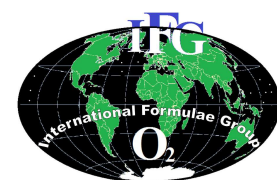

Available online at http://ajol.info/index.php/ijbes

Int. J. Biol. Chem. Sci. 8(2): 831-842, April 2014

ISSN 1997-342X (Online), ISSN 1991-8631 (Print)
International Journal

of Biological and

Chemical Sciences

Review

http://indexmedicus.afro.who.int

\title{
Agrochemicals use in horticulture industry in Tanzania and their potential impact to water resources
}

\author{
Emmy LEMA*, Revocatus MACHUNDA and Karoli Nicholas NJAU \\ Nelson Mandela African Institution of Science and Technology (NM-AIST), Department of Water, \\ Environmental Science and Engineering, P. O. Box 447, Arusha, Tanzania. \\ ${ }^{*}$ Corresponding author; E-mail: lemae@nm-aist.ac.tz; Mobile+255 713991877.
}

\begin{abstract}
The objective of this review was to analyze the existing information on the use of agrochemicals (Fertilizers and Pesticides) in the Tanzanian horticulture industry especially the Northern regions and their potential to impacting water resources. Agrochemicals play an important role in horticulture, and have been widely used in Tanzania for crop protection and increasing productivity. Apart from these benefits, agrochemicals have the potential to impair the quality of water resources for different end uses. Majority of communities in Tanzania depend on surface water from rivers and lakes for potable uses such as washing, drinking and domestic animals also drink from these sources. Reports from studies done in Northern Tanzania have indicated the presence of significant levels of pesticides, phosphates and nitrates in surface and groundwater. It is apparent that most of the horticultural farms in Northern Tanzania are located on gently sloping land adjacent to water bodies. Thus discharges of wastewaters from horticulture farms may affect the quality of water resources through run-off and groundwater through infiltration if proper management of the agrochemicals is not well adhered to. The agrochemicals that have been widely used and identified as potential environmental pollutants from their use as horticultural chemicals are reviewed. The potentially adverse impacts of these agrochemicals to water resources are discussed. The review concludes with a discussion of the directions for further investigation.
\end{abstract}

(C) 2014 International Formulae Group. All rights reserved.

Keywords: Pesticides, fertilizers, wastewater, horticulture, environment.

\section{INTRODUCTION}

Agrochemicals are commercially produced, usually synthetic chemical compounds such as fertilizers, pesticides including insecticides, herbicides, fungicides that are used to improve the production of crops in agricultural industries. The current system of agriculture industry in Tanzania promotes the reliance on agrochemicals, both synthetic fertilizers and pesticides. Agriculture, which by definition includes horticulture, continues to play a predominant role in Tanzanian economy. It contributes about $45.6 \%$ of the Gross Domestic Product (GDP), generates about $60 \%$ of the total export earnings and employs about $80 \%$ of the labour force in 2005 (MAFS, 2007).

The existing diversity of agro-climatic zones in Tanzania implies that wide ranges of horticultural crops can be grown. Despite high production potential in many parts of the country at the moment, horticulture is well 
developed in the Northern regions (like Arusha, Kilimanjaro and Tanga) and the Southern highlands (Mbeya and Iringa). However, more than $85 \%$ of commercial horticultural investment is concentrated in the Northern part of Tanzania, especially in Arusha and Kilimanjaro regions. The lack of proper infrastructure, access to markets and investment programmes form major bottlenecks to other regions with potential to develop commercial and export-oriented horticulture industries (Nyambo and Verschoor, 2005). The development of the horticulture industry in Tanzania has had a positive impact on people in Northern regions through employment generation over a period when employment in another important export sector such as coffee went down significantly.

The commercial horticulture crops grown in these regions include fruits, vegetables, spices, herbs and ornamental (flowers). In recent years, there has been an increase in demand and production of horticulture products (ESRF, 2010). However, the horticultural productivity in a tropical country like Tanzania is severely limited by incidences of pests and diseases affecting crops. To cope with pest and disease problems, farmers rely heavily on the use of pesticides. Different classes of pesticides have been commonly used such as organochlorines, carbamates, organophorsphorous, pyrethroids and atrazines (Henry and Kishimba, 2002; Ngowi, 2007; Nonga et al., 2011). Some of the organochlorine pesticides like dichlorodiphenyltrichloroethane (DDT), $\gamma$ hexachlorocyclohexane $(\mathrm{HCH})$ and aldrin are reported being persistent in the environment and have been banned in developed countries in Europe and America in accordance with the Stockholm Convention on persistent organic pollutants (POPs) (Vijgen et al., 2011). Tanzania banned the use of DDT in agriculture in the early 1990s (Henry and Kishimba, 2003) and the pesticides were replaced by pyrethroids such as cypermethrin, deltamethrin, permethrin and cyhalothrin. Other pesticides include organochlorines like endosulfan and chlorothalonil; organophosphorous insecticides (chlorpyrifos, dimethoate, profenofos, diazinon and fenitrothion) and carbamates (mancozeb, carbaryl and metalaxy). However, some of other pesticides like $\mathrm{HCH}$ are still used on horticulture crops in Tanzania (Kihampa et al., 2010a, 2010b) despite the fact that this pesticide is not registered by the Tanzania licensing authority (Anon, 2002). They are being used because of their low cost and usefulness in agriculture (Agenda, 2006). Some of the pesticides are imported and sold under different names (Henry and Kishimba, 2003).

Despite the problems of pests and diseases affecting crop productivity, Tanzania like many other Sub-Saharan African (SSA) countries is reported to experience soil fertility decline (Ehui and Pender, 2005). Most soils have low nutrient content, particularly in nitrogen and phosphorus (Ndakidemi and Semoka, 2006; Hartemink, 2006). The decline in soil fertility is among the reasons for decline in crop productivity and yields in several SSA countries. The use of fertilizers has been an important input in agriculture to improve soil fertility (Todd et al., 2012) and consequently increase productivity (Zhu and Chen, 2002). Globally, the use of fertilizers has increased tremendously and is generally responsible for the green "revolution" i.e. the massive increase in production obtained from the same surface area of land with the help of inorganic fertilizers and intense irrigation. Studies done in China reported a significant positive linear correlation between annual food production and chemical fertilizer nitrogen consumption for a consecutive period of 50 years (Zhu and Chen, 2002). The most commonly used fertilizers include different nitrogen and phosphate fertilizers. However, in SSA countries, the low productivity of crops has been linked to poor resource endowments, minimal use of inputs (fertilizer, improved seeds, and irrigation), and adverse policies (Kwadwo et al., 2012).

Whilst agrochemicals have been the most common strategy for fertilizing soils, control pests and crop diseases, but also constitute a major factor affecting the 
environment and human health. Cases of organochlorine pesticide contamination and human health impacts have been reported around the world including in developing countries like Tanzania (Henry and Kishimba, 2002; Weiss et al., 2006; Liney et al., 2006; Kihampa et al., 2010a). The consequences of excessive and inappropriate use of nitrogen and phosphorus fertilizers in agriculture can significantly contribute to surface and underground water pollution. Drinking water polluted with nitrates poses health risks, especially to children being vulnerable to Methaemoglobinemia. Nutrients from agricultural activities have resulted in eutrophication of water bodies (Kalff, 2002; Kulekana, 2004; Nonga et al., 2011). Once the quality of water is changed by the presence of these agrochemicals, it becomes potentially harmful to life forms, instead of sustaining them. Thus, despite their role in the horticulture industry, evaluating their potential to impacting the water resources especially in the Northern Tanzania is of great importance. This will make available the information about the potential threat they may pose to both surface and groundwater sources. This review therefore analyses their types and quantities in use and pattern of use so as to evaluate any potential for polluting such water sources. It finally recommends on the best practices and measures that need to be taken to prevent potential environmental damage.

\section{Agrochemicals in use in Tanzania Fertilizers imports and use}

In Tanzania, most of the fertilizers are mainly an imported commodity with exception of Minjingu Rock Phosphate (MRP) which is obtained locally from major deposits of phosphate produced in the Northern part of Tanzania. Over the years, fertilizer imports have increased and can be attributed to the Government supported input subsidy program, the National Agricultural Input Voucher Scheme (NAIVS). The program was first started in 2007 and was then scaled up in 2009. In 2007, Tanzania imported 169,027 metric tons of fertilizer, an amount that increased to 318,060 tons in 2011 (World Bank, 2012) as shown in Figure 1.

Alongside imports, fertilizer use has also increased since the re-introduction of subsidy on fertilizer use (MAFC, 2011). From 2008 to 2010, there was a sharp increase in total fertilizer use (Figure 1). Despite this increase, the average fertilizer application rate of $19.3 \mathrm{~kg} / \mathrm{ha}$ in Tanzania is lowest compared to other countries in Africa (World Bank, 2012). For example, Kenya and South Africa's fertilizer application rates are 100 $\mathrm{kg} / \mathrm{ha}$ and $20 \mathrm{~kg} / \mathrm{ha}$ respectively. The reason for the low usage in Tanzania could be attributed by the fact that the country's agriculture is dominated by small-scale subsistence farming and that most farmers do not have the capacity to purchase fertilizers and also they have not been sensitized on the benefits of using artificial fertilizers. On the other hand, in 2011 the use of fertilizers dropped due to prices being high as shown in Figure 1.

\section{Types and quantities of fertilizers used in Tanzania}

Inorganic fertilizers commonly used in

Tanzania include Urea, Di-Ammonium Phosphate (DAP), Calcium Ammonium Nitrate (CAN), various Nitrogen, Phosphorus and Potassium (NPK) grades, Muriate of Potash (MOP); comprising $71 \%$ of imported fertilizers in 2009/10 and Minjingu Rock Phosphate (MRP). Urea and DAP accounted for about half the total volume of fertilizer used in 2009/10. This is because the NAIVS vouchers subsidize for their purchase and hence farmers are having difficulty to pay the portion of the fertilizer cost not covered by the subsidy. NPK fertilizers consistently account for $21 \%$, MRP (13\%), CAN about 9\%, Sulphate of Ammonia (S/A) 5.1\%, other fertilizers $0.9 \%$ and Triple Super phosphate (TSP) $0.3 \%$ (MAFC, 2011). Low quantities of foliar fertilizers (liquid) are used mainly in horticulture industries. These types and quantities are as summarized in Figure 2. 


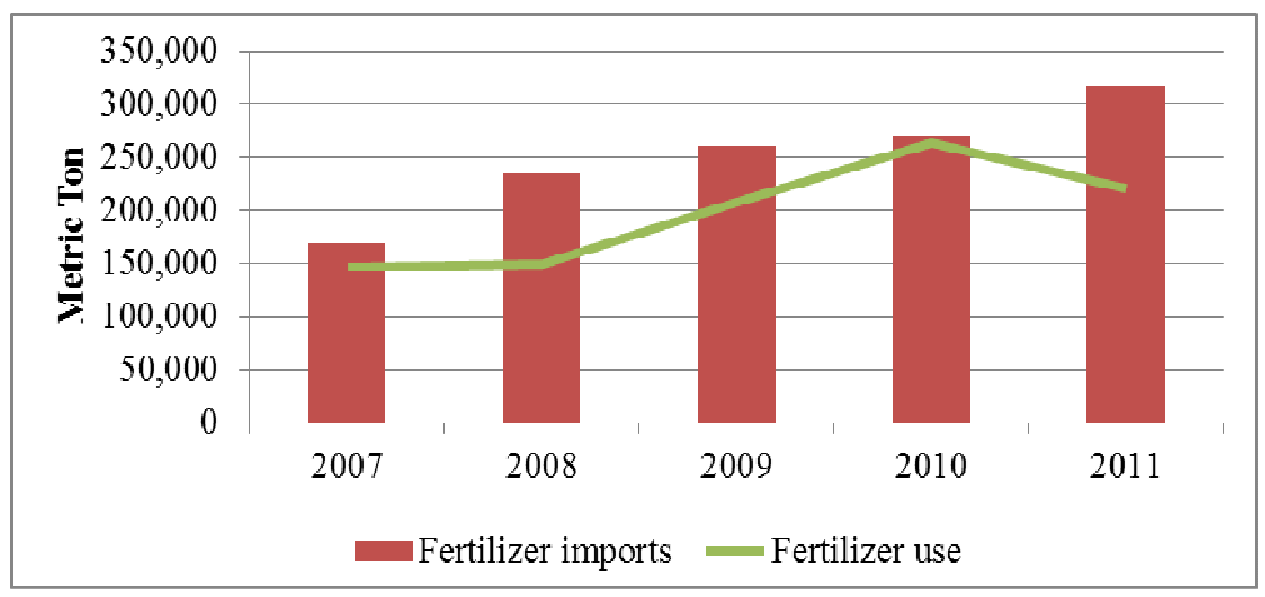

Figure 1: Fertilizer imports and use in Tanzania. Source: World Bank, 2012.

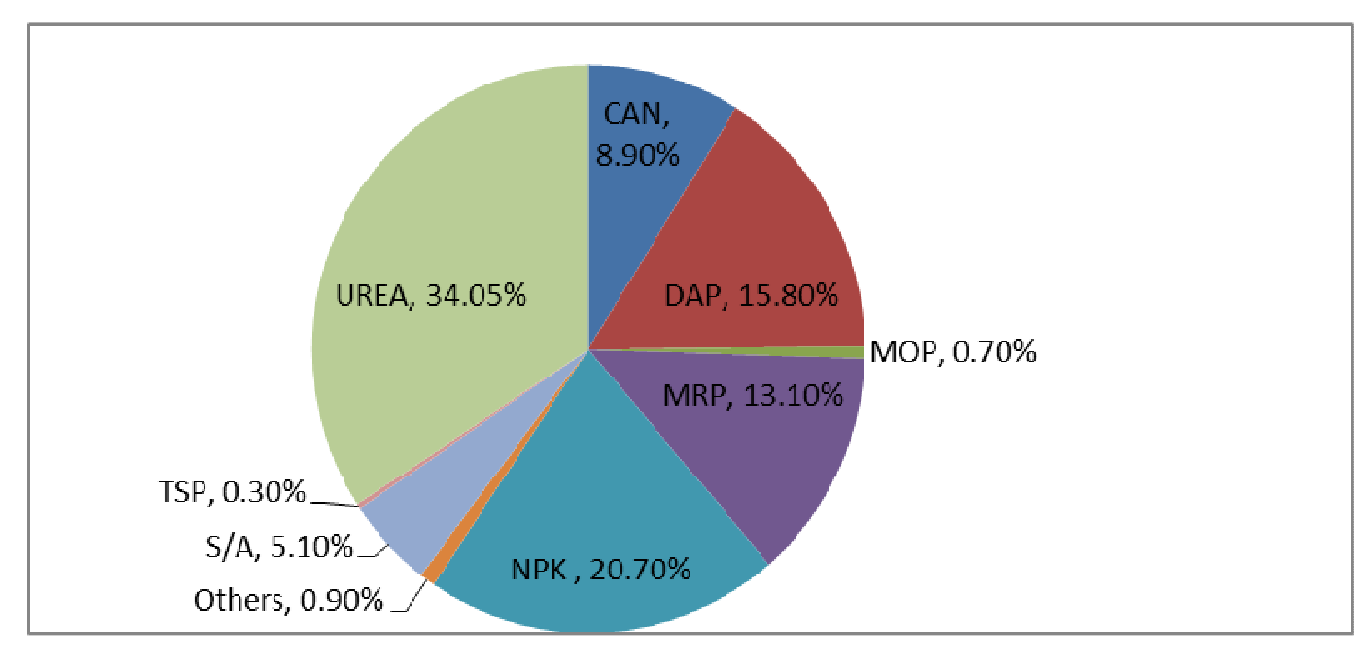

Figure 2: Quantity of fertilizer use and type share to the total 2009/10. Source: Ministry of Agriculture, Food Security and Cooperatives (MAFC, 2011), Tanzania.

\section{Pesticide use in Tanzania}

Pesticides are defined by the Tropical Pesticide Research Institute (TPRI) Act No.18 of 1979 as "any matter of any description (including acaricides, arboricides, herbicides, insecticides, fungicides, molluscides, nematicides, hormonal sprays and defoliants) used or intended to be used, either alone or together with other material substances) for the control of weeds, pest and disease in plants, or for the control of the external vectors of veterinary or medical disease and external parasites of man or domestic animals or for the protection of any food intended for human or human consumptions" (Agenda, 2006).

A large number of pesticides have been extensively used to maintain high agricultural yields and eradicate vector-borne diseases in Tanzania in the last decades (Agenda, 2006). Although it is not possible to obtain figures for quantity of pesticides used or sold to the 
agricultural sector, however, the available information indicates that Tanzania imports over tons of pesticides from European and North American countries (Kaoneka and Ak'habuhaya, 2000) and the importation rose following the liberalization of agrochemicals trade in the country (Ngowi, 2002). From 2000 to 2003 the imports of pesticides increased from 500 to 2500 tons per year. By the year 2006, a total number of brands of registered pesticides were 682 (Agenda, 2006). It is estimated that $81 \%$ of pesticides are used in livestock and agricultural sectors and only $19 \%$ is used for non-agricultural purposes (Agenda, 2006).

\section{Types of pesticides used in Tanzanian horticultural settings}

The horticulture industry in Tanzania mostly uses different classes of pesticides and herbicides such as organochlorines, carbamates, organophorsphorous, pyrethroids and atrazines (Ngowi, 2002; Agenda, 2006; Nonga et al., 2011). Table 1 shows different types of pesticides used in Northern Tanzania (Ngowi, 2002; Agenda, 2006; Nonga et al., 2011). It is estimated that more than 40 different pesticides are used in horticulture of which the most widely used are insecticides (59\%), fungicides (29\%), with the remaining (12\%) being herbicides (Ngowi, 2007). Insecticides are mostly used because insect pests are the most serious problem in horticulture production. Fungicide usage indicates that fungal attacks rank second to insect pests. Herbicides are least in use because weeding can be easily done manually by deploying community members (Ngowi, 2007). The most widely used pesticide types are organophosphates (OP), carbamates and pyrethroids. Although Tanzania has a regulatory system on registration and trading of pesticides, however, the pesticides which are imported and used in Tanzania includes both the registered and unregistered (Table 1). The use of unregistered or banned pesticides can cause unreasonable risk to the environment and human health. Smallholder horticulture farmers in Tanzania have been reported to lack adequate knowledge in proper use and management of pesticides (Ngowi, 2007; Nonga et al., 2011). Improper use of pesticide has been found to cause various forms of cancer, birth defects, sterility, damage of liver, kidney, neural organs and deaths (Ngowi, 2002; McCauley et al., 2006; Soltaninejad et al., 2007; Weiss, et al., 2007; Aktar et al., 2009).

Notwithstanding these effects, Table 1 shows that some of the pesticides used in horticulture include those which are categorized by WHO as Class 1a (extremely hazardous), Class 1b (highly hazardous). Respective examples include aldicarb and carbofuran which belong to the carbamate class of pesticides and are marked as "restricted use pesticides" by the US Environmental Protection Agency (USEPA). In addition, majority of the pesticides used are in Class II (moderately hazardous) and a few in Class III (slightly hazardous) or U (Unlikely to present acute hazard). The pesticides used have implications on health because some of them are classified to be carcinogenic, cholinesterase inhibitors and others suspected to be endocrine disruptors. A few examples include aldicarb, carbofuran, cypermethrin and dimethoate classified by the USEPA as possible human carcinogens and cholinesterase inhibitors. Endosulfan, lambdacyhalothrin and chlorpyrifos are listed by WHO as moderately hazardous pesticides though they are suspected to be endocrine disrupting chemicals. Due to the associated risks of toxicity, these pesticides have been banned in the European Union, but are still being used in developing country like Tanzania. There are strong indications that there are substantial human health problems associated with the use of pesticides in horticultural farming in Tanzania but these are inadequately documented (Ngowi, 2007). 
Table 1: Types of pesticides used in horticulture in Northern Tanzania.

\begin{tabular}{|c|c|c|c|c|c|c|}
\hline Trade name & Active ingredient & Chemical group $^{\text {a }}$ & WHO Class ${ }^{\text {b }}$ & Health effects ${ }^{c}$ & Amount used /yr & Registration status \\
\hline \multicolumn{7}{|c|}{ Insecticides } \\
\hline Thionex / Thiodan & Endosulfan & $\mathrm{OC}$ & II & Suspected EDC & $940 \mathrm{~L}$ & Registered \\
\hline Selectron & Profenofos & OP & II & $\mathrm{CI}$ & $619 \mathrm{~L}$ & Registered \\
\hline Karate & Lambda-cyhalothrin & $\mathrm{P}$ & II & Suspected EDC & $565 \mathrm{~L}$ & Registered \\
\hline Dimethoate & Dimethoate & $\mathrm{OP}$ & II & $\mathrm{CI}$ & $154 \mathrm{~L}$ & Registered \\
\hline Bamethrin & Deltamethrin & $\mathrm{P}$ & II & $\mathrm{CI}$ & $150 \mathrm{~L}$ & Registered \\
\hline Helarat & Lambda-cyhalothrin & $\mathrm{P}$ & II & Suspected EDC & $175 \mathrm{~L}$ & Registered \\
\hline Rogor & Dimethoate & OP & II & $\mathrm{CI}, \mathrm{C}$ & $128 \mathrm{~L}$ & Registered \\
\hline Dursban & Chlorpyrifos & $\mathrm{OP}$ & II & $\mathrm{EDC}, \mathrm{CI}$ & $108 \mathrm{~L}$ & Registered \\
\hline Antokil & Chlorpyrifos & $\mathrm{P}$ & II & $\mathrm{EDC}, \mathrm{CI}$ & $165 \mathrm{~L}$ & Registered \\
\hline Diazinon & Diazinon & OP & II & CI & $120 \mathrm{~L}$ & Unregistered \\
\hline Profecron & Profenofos & $\mathrm{OP}$ & II & $\mathrm{CI}$ & $143 \mathrm{~L}$ & Registered \\
\hline Polytrin & Cypermethrin & $\mathrm{OP}$ & $\mathrm{U}$ & $\mathrm{C}$ & NK & Unregistered \\
\hline Selecron & Profenofos & $\mathrm{OP}$ & II & $\mathrm{CI}$ & NK & Registered \\
\hline Furadan & Carbofuran & $\mathrm{C}$ & IB & CI, EDC & $254 \mathrm{Kg}$ & Registered \\
\hline Malathion & Malathion & OP & III & CI & $192 \mathrm{Kg}$ & Registered \\
\hline Shumba super & Fenitrothion + Deltamethrin & $\mathrm{OP} / \mathrm{P}$ & II & $\mathrm{CI}$ & $145 \mathrm{Kg}$ & Registered \\
\hline Permethrin & Permethrin & $\mathrm{P}$ & II & Neurotoxin & NK & Unregistered \\
\hline Propamocarb hydrochloride & Pyrethrins & $\mathrm{P}$ & No class & & NK & Unregistered \\
\hline Termik & Aldicarb & $\mathrm{C}$ & IA & $\mathrm{EDC}, \mathrm{CI}$ & NK & Unregistered \\
\hline Diazol & Diazinon & OP & II & $\mathrm{CI}$ & NK & Unregistered \\
\hline Carbaryl & Carbaryl & $\mathrm{C}$ & II & $\mathrm{CI}$ & NK & Unregistered \\
\hline \multicolumn{7}{|c|}{ Herbicides } \\
\hline Kalachi & Glyphosate & OP & III & & $452 \mathrm{~L}$ & Registered \\
\hline
\end{tabular}


E. LEMA et al. / Int. J. Biol. Chem. Sci. 8(2): 831-842, 2014

\begin{tabular}{|c|c|c|c|c|c|c|}
\hline Balton & 2-4-D Amine & AA & $\mathrm{U}$ & & 331 & Registered \\
\hline Roundup & Glyphosate & $\mathrm{OP}$ & III & & $338 \mathrm{~L}$ & Registered \\
\hline Mamba & Glyphosate & $\mathrm{OP}$ & III & & $200 \mathrm{~L}$ & Registered \\
\hline \multicolumn{7}{|c|}{ Fungicides } \\
\hline Farmerzeb & Mancozeb & $\mathrm{C}$ & II & CI & $501 \mathrm{Kg}$ & Registered \\
\hline Red copper & Copper oxide & $\mathrm{Cu}$ & III & & $560 \mathrm{Kg}$ & Registered \\
\hline Cuprocaffaro & Copper oxychloride & $\mathrm{Cu}$ & II & & $210 \mathrm{Kg}$ & Registered \\
\hline Blue copper & Copper sulphate & $\mathrm{Cu}$ & II & & $370 \mathrm{Kg}$ & Registered \\
\hline Dithane & Mancozeb & $\mathrm{C}$ & III & CI & $1596 \mathrm{Kg}$ & Registered \\
\hline Antracol & Dithiocarbamate & $\mathrm{D}$ & III & & $165 \mathrm{~L}$ & Registered \\
\hline Ridomil & Metalaxyl / Mancozeb & $\mathrm{C}$ & IIB & $\mathrm{C} / \mathrm{CI}$ & $127 \mathrm{Kg}$ & Registered \\
\hline Bayleton & Tridimefon & $\mathrm{T}$ & III & PC & $65 \mathrm{~L}$ & Registered \\
\hline Indofil & Mancozeb & $\mathrm{C}$ & III & $\mathrm{CI}$ & $52 \mathrm{Kg}$ & Registered \\
\hline Ivory & Mancozeb & $\mathrm{C}$ & IB & CI & $145 \mathrm{Kg}$ & Registered \\
\hline Linkonil & Chlorothalonil & $\mathrm{OC}$ & NK & $\mathrm{C}$ & $63 \mathrm{Kg}$ & Registered \\
\hline Thiovit & Sulphur & $S$ & $\mathrm{U}$ & Irritant & $124 \mathrm{Kg}$ & Registered \\
\hline Bravo & Chlorothalonil & $\mathrm{OC}$ & II & $\mathrm{C}$ & $115 \mathrm{Kg}$ & Registered \\
\hline Rova & Chlorothalonil & $\mathrm{OC}$ & NK & $\mathrm{C}$ & $12 \mathrm{Kg}$ & Registered \\
\hline Meltatox & Triforine & & $\mathrm{U}$ & Irritant & NK & Unregistered \\
\hline Milthane & Mancozeb & $\mathrm{C}$ & $\mathrm{U}$ & $\mathrm{CI}$ & NK & Unregistered \\
\hline
\end{tabular}

a $\mathrm{C}=$ carbamate, $\mathrm{D}=$ dithiocarbamate, $\mathrm{P}=$ pyrethroid, $\mathrm{OP}=$ organophosphate, $\mathrm{A}=$ acylalanine, $\mathrm{AA}=$ aryloxyalkanoic acid, $\mathrm{Cu}=$ inorganic copper, $\mathrm{T}=$ tridimefon, $\mathrm{S}=$ suphur.

b $1 \mathrm{a}=$ extremely hazardous; $1 \mathrm{~b}=$ highly hazardous; $\mathrm{II}=$ moderately hazardous; $\mathrm{III}=$ slightly hazardous; $\mathrm{U}=$ unlikely to present acute hazard in normal use, $\mathrm{NK}=$ not known

${ }^{c} \mathrm{CI}=$ Cholinesterase inhibitor, $\mathrm{C}=$ Carcinogenic, $\mathrm{PC}=$ Possible carcinogenic, $\mathrm{EDC}=$ endocrine disrupting chemical.

Source: (Agenda, 2006; Ngowi et al., 2007 ; Nonga et al., 2011). 


\section{Potential impacts of agrochemicals to water resources}

Agriculture has been identified as the major user of water in most countries (OECD, 2010) and also contributes to water pollution from excess nutrients, pesticides and other pollutants. Majority of the farms are therefore located in areas where water supply is assured. Sources of water include springs, rivers and boreholes. Consequently, discharges of untreated and poorly treated wastewaters from horticulture farms may affect the quality of water resources for different end uses. Rural communities depend on surface water from rivers and lakes for potable uses such as washing, drinking and domestic animals also drink from these sources. Horticulture activities can contribute to water quality impairment through the release of agrochemicals particularly nutrients from inorganic fertilizers and pesticides. Majority of horticulture farmers in Tanzania lack appropriate knowledge of proper management of agrochemicals (Ngowi, 2007) and have been using them without proper advice from agriculture officers (Nonga, et al., 2011). Unlike the misuse including overdosing, farmers apply agrochemicals by use of Knapsack sprayers and the sprayers washing is often done in rivers. Also, the remnants of these agrochemicals are discarded by pouring them on the ground or burying (Nonga, et al., 2011). Empty containers are disposed within farms or in designated waste pits. This improper management of agrochemicals may cause pollution of water resources. Many of these pollutants may reach surface and ground water resources through runoff, discharges and percolation, where they can cause significant water pollution (Aktar et al., 2009). Several authors have discussed research on the potential for agrochemicals pollution by fertilizers and pesticides used in horticulture. A summary of the key findings reviewed is provided hereafter.

\section{Eutrophication}

Eutrophication is generally defined as an increase in nutrients such as nitrogen and phosphorus in aquatic ecosystems that lead to increase in primary productivity. The consequences from this eutrophication are algal blooms increased water turbidity, oxygen depletion and fish deaths (Kalf, 2002). Monitoring of rivers and lakes in many parts of the world including Tanzania has shown significant concentration of nutrients. For example in Lake Manyara in Tanzania, big blooms of blue green algae (cyanobacteria) have been observed in the lake, and this was associated with high nutrient loads and eutrophication. High levels of phosphates were detected in the lake and were associated with high uses of fertilizers (Nonga et al., 2011). Fertilization and eutrophication are among the factors reported to foster increases of phytoplankton in particular in water bodies and other water weeds in lakes (Nonga et al., 2011). The eutrophication effect of Lake Victoria in Tanzania is also anticipated to be arising from the increased in flow of nutrients, particularly nitrates and phosphates (Kulekana, 2004).

\section{Nitrate pollution}

Excess application of inorganic nitrogenous fertilizers in horticulture can contribute directly to water nitrate pollution through fertilizer use. When too much nitrogen fertilizer is applied to crop soils, the excess that is not used by the plants eventually runs-off polluting groundwater, rivers, and lakes. Groundwater wells in vegetable farming areas in the Philippines were polluted with nitrates levels above WHO limits (Tirado, 2007). This pollution was related to intensive use of nitrogen fertilizers are applied in excess. Drinking water polluted with nitrates poses health risks, especially to children. A known human health risk is nitrate contamination in infant methemoglobinemia (blue-baby syndrome), a condition where nitrates are converted into nitrites in the digestive system, impairing the ability of infants' blood to carry oxygen. Concentration of nitrates in drinking water may be below levels at which acute health effects have been observed. However, continued exposure may result in chronic effects (i.e., reproductive 
impairments, cancer, etc.) to humans or other organisms.

\section{Pesticide pollution}

The contamination of the environment with pesticide residues in environmental matrices could result in water pollution and thus endangering human health and non-target species. Cases of water pollution as well as soil and food contamination in Tanzania and elsewhere have been documented (Henry and Kishimba, (2002); Hellar et al., 2005; Mihale, 2004; Aktar et al., 2009; Kihampa et al., 2010a, 2010b; Chowdhury et al., 2012) and some health effects have been correlated with pesticide pollution (Ngowi, 2002; Agenda, 2006). As part of this review, surface water and ground water is the compartment of concern.

\section{Surface water contamination}

Pesticides can reach surface water through runoff from wastewater effluents and from soil deposits. Around the globe, pesticides and metabolites have been detected in major rivers and lakes from different countries. Water samples collected from paddy and vegetable fields in Bangladesh were reported to be highly polluted with pesticide residues (Chowdhury et al., 2012). The presence of these pesticide residues were attributed by their intense use by the farmers living in the sampled areas.

In studies conducted in Tanzania, significant levels of pesticide residues in water, soil and sediments have been reported (Henry and Kishimba, 2002; Hellar and Kishimba, 2005; Kihampa et al., 2010a, $2010 \mathrm{~b}$ ). Their analysis indicated among other pesticides, residues of DDT and its metabolites DDE and DDD; $\mathrm{HCH}$ isomers and endosulfan in water, sediments and soil samples from agriculture farms despite the ban of these pesticides in Tanzania (TPRI, 2002). Similar results of organochlorine pesticide such as DDT and $\mathrm{HCH}$ were also determined in water sampled in Simiyu river catchment (Tributary Lake Victoria) (Rwetabula, 2005). The Simiyu catchment was considered to be one of the main contributors to the deterioration of Lake Victoria quality due to agricultural activities using agrochemicals (Ningu, 2000). In Northern part of Tanzania, pesticide residues such as lindane, chlorpyrifos, endosulfan, DDE and DDD was determined in soil samples collected from tomato fields in Arusha (Kihampa et al., 2010a). In addition, residues of organochlorine pesticides aldrin, dieldrin, heptachlor epoxides, $\mathrm{HCH}$, endosulfan and DDT were detected in river water near Tanganyika sugar cane plantations (TPC) in Kilimanjaro, with mean concentrations ranging from 1.1 to $636.7 \mathrm{ng} / \mathrm{l}$ (Hellar and Kishimba, 2005). These findings are similar to those observed in a study conducted by Kihampa et al. (2010b) where significant concentrations of lindane, chlorpyrifos, and endosulfan were detected in irrigation effluent from horticulture farms in Arusha. The high levels of pesticides detected were associated to the intensity of agricultural activities due to pesticide use as well as pesticide application history among the areas.

Contamination of the water bodies by pesticides, either directly or indirectly, can lead to ecotoxicological effects to aquatic organisms, wildlife as well as human health if used for public consumption (Soltaninejad et al., 2007). Toxic pesticide residues which can also pollute water bodies used for drinking are toxic to fish and can accumulate in many aquatic organisms and affect the top predators. Historically, most of the fish in Europe's Rhine River were killed by the discharge of pesticides, and at one time, fish populations in the Great Lakes became very low due to pesticide contamination (Adedeji and Okocha, 2012). In the United States of America, there were incidences of DDT pollution that caused thinning of eggshells and the migration of the bald eagle population (Liroff, 2000).

\section{Ground water contamination}

Groundwater pollution due to pesticides is a worldwide problem. Over the past two decades, pesticides and their metabolites have been detected in ground water. During one survey in India, $58 \%$ of drinking water samples drawn from various 
hand pumps and wells around were contaminated with organochlorine pesticides above the EPA standards (Kole and Bagchi, 1995).

Similar contamination has also been reported in Tanzania. Some wells in Tanzania which are also used for domestic purposes by villagers are contaminated by DDT with mean total levels of $9 \mu \mathrm{g} / \mathrm{l}$ (Mihale and Kishimba, 2004). This concentration is higher than those allowed by the WHO for drinking water, therefore is a risk to consumers.

In addition, analyses of ground water in Tanzania indicated some trace concentrations of endosulfan sulphate (Henry and Kishimba, 2002) and Lindane (Mihale and Kishimba, 2004). Endosulfan is an organochlorine pesticide which is persistent to environmental degradation as compared to other classes of pesticide and thus has the potential to bioaccumulate in fish, wildlife and human tissues and cause toxicity effects. Notwithstanding these effects, endosulfan is among the insecticides reported to be used intensively in horticulture crops in Northern Tanzania. Endosulfan sulphate was the most abundant residue detected in horticulture fields in the area and high levels have been reported in environmental matrices (Kihampa et al., 2010a, 2010b). The high uses of these pesticides call for the need to monitor their residues in the environment because once the ground water source is polluted with pesticides, it may take many years for the contamination to dissipate or be cleaned up (US EPA, 2001). Clean-up may also be very costly and complex, if not impossible especially for a developing country like Tanzania.

\section{Conclusion}

Agrochemicals are widely used in Tanzania horticulture and their use has significantly increased in the recent years. Many important benefits are achieved by the use of agrochemicals such as increased yields of plant crops. However, agrochemical use comes at a significant cost. Indiscriminate use of certain agrochemicals like pesticides and fertilizers has been associated with contamination of the environment and potential impacts to water resources. There are significant contribution of fertilization and eutrophication of some rivers and lakes in Tanzania from high use of nitrogen and phosphate fertilizers in areas with intense horticulture. Pesticide residues have been detected in soil, surface water and ground water across countries. Results from different literature show that organochlorine pesticides are by far the most frequently detected in environmental samples. These chemicals are persistent in the environment and thus there is a need to ensure regulations governing their ban for use are strictly enforced.

Farmer's limited knowledge on proper use and management of agrochemicals is among the factors that cause indiscriminate use and pollution of the environment. However, opportunities for preventing pollution by these agrochemicals include the following measures:

- Education and sensitization of farmers against illegal and indiscriminate use of agrochemicals (pesticides and fertilizers);

- Promotion of integrated pest management (IPM) to ensure responsible use of pesticides so as to minimize potential adverse impacts on human health and environment;

- Continual monitoring of levels of agrochemicals in different environmental compartments for regulatory control;

- $\quad$ Further studies are recommended in particular on risk assessment and ecotoxicological impacts of agrochemicals in Tanzania as information is currently scant.

\section{REFERENCES}

Adedeji OB, Okocha RO. 2012. Overview of pesticide toxicity in fish. Advances in Environmental Biology, 6(8): 2344-2351.

AGENDA. 2006. Pesticide and Poverty. A case study on trade and utilization of pesticides in Tanzania. Implication to stockpiling. Final Report, published by Agenda for Environment and Responsible Development.

Agrawal A, Pandey, SR, Sharma B. 2010. Water Pollution with Special Reference 
to Pesticide Contamination in India. Journal of Water Resource and Protection, 2(5): 432-448.

Aktar W, Sengupta D, Chowdhury A. 2009. Impact of pesticides use in agriculture: Their benefits and hazards. Interdisc Toxicol., 2(1): 1-12.

Anderson DM, Glibert PM, Burkholder JM. 2002. Harmful Algal Blooms and Eutrophication: Nutrient Sources, Composition, and Consequences. Estuaries, 25(4b): 704-726.

Anon. 2002. List of Pesticides registered in Tanzania. Tropical Pesticides Research Institute (TPRI).

Chowdhury MAZ, Banik S, Uddin B, Moniruzzaman M, Karim N, Gan SH. 2012. Organophosphorus and carbamate pesticide residues detected in water samples collected from paddy and vegetable fields of the Savar and Dhamrai upazilas in Bangladesh. Int. J. Environ. Res. Public Health, 9: 3318-3329.

Ehui S, Pender J. 2005. Resource degradation, low agricultural productivity, and poverty in Sub-Saharan Africa. Pathways out of the spiral. Agricultural Economics, 32: 225-245.

ESRF. 2010. Strengthening Micro-Enterprises in Tanzania: The Case of Small-Scale Vegetable Farmers in Arusha. Final Report, Economic and Social Research Foundation (ESRF). Retrieved from http://www.tzonline.org/pdf/microentepri se.pdf.

Hartemink AE. 2006. Assessing Soil Fertility Decline in the Tropics Using Soil Chemical Data. Advances in Agronomy, 89: 179-225.

Hellar H, Kishimba MA. 2005. Pesticide residues in water from TPC sugarcane plantations and environs, Kilimanjaro region, Tanzania. Tanz. J. Sci., 31: 13-22.

Henry L, Kishimba MA. 2003. Levels of Pesticides in water, soil and sediments from southern Lake Victoria and its Basin. Tanz. J. Sci., 29(1): 77-90.

Kalff J. 2002. Limnology. Inland Water Ecosystems. Pretence-Hall: New Jersey.
Kihampa C, Mato RR, Mohamed H. 2010a. Residues of Organochlorinated Pesticides in Soil from Tomato Fields, Ngarenanyuki, Tanzania. J. Appl. Sci. Environ. Manage., 14(3): 37-40.

Kihampa C, Mato RR, Mohamed H. 2010b. Levels of pesticide residues in irrigation effluent from tomato fields in Owiro Estate, Tanzania. Int. J. Biol. Chem. Sci., 4(3): 601- 607.

Kole RK, Bagchi MM. 1995. Pesticide residues in the aquatic environment and their possible ecological hazards. $J$. Inland Fish Soc. India, 27(2): 79-89.

Kulekana J. 2004. Levels of Nitrate and Phosphate in some satellite lakes within the Lake Victoria Basin, Tanzania. Tanz. J. Sci., 30(1): 1-9.

Kwadwo AO, Jemaneh S. 2012. Increasing Agricultural Productivity and Enhancing Food Security in Africa-New Challenges and Opportunities. Synopsis of an International Conference. International Food Policy Research Institute 2033 K Street: NW, Washington, DC 20006-1002 USA; 5.

Liroff RA. 2000. Balancing risks of DDT and malaria in the global POPs treaty. Pesticide Safety News, 4: 3-7.

MAFS. 2002. Basic Data- Agriculture Sector 1994/95-2000/2001. Statistics Unit, Ministry of Agriculture and Food Security (MAFS), Dar es Salaam, Tanzania, p. 72.

McCauley A, Linda, Anger KW, Keifer M, Langley R, Robson GM. 2006. Studying health outcomes in farm worker populations exposed to pesticide. Environ. Health Perspec., 114: 6-8.

Mihale MJ, Kishimba MA. 2004. Contamination of water and sediments by obsolete pesticides at Vikuge farm, Kibaha District, Tanzania. Tanz. J. Sci., 30(2): 21-31.

Ndakidemi PA, Semoka JMR. 2006. Soil fertility in Western Usambara Mountain, Northern Tanzania. Pedosphere, 16(2): 237-244.

Ngowi AVF, Mbise TJ, Ijani ASM, London L, Ajayi OC. 2007. Smallholder vegetable 
farmers in Northern Tanzania: Pesticides use, practices, perceptions, cost and health effects. Crop Prot., 26(11): 16171624.

Ngowi AVF. 2002. Health Impact of Pesticides in Agriculture in Tanzania. $\mathrm{PhD}$ thesis, Tampere University, Finland, p. 70 .

Ningu J. 2000. An inventory of agrochemicals in the Lake Victoria basin, Mwanza, Tanzania. Lake Victoria Environmental Management Project (LVEMP), Tanzania.

Nonga HE, Mdegela RH, Lie E, Sandvik M, Skaare JU. 2011. Assessment of farming practices and uses of agrochemicals in Lake Manyara basin, Tanzania. African Journal of Agricultural Research, 6(10): 2216-2230.

Nyambo B, Verschoor R. 2005. Partnership for Market Access; towards a sustainable market-oriented horticultural sector in Tanzania. The export horticulture in Tanzania. Wageningen UR Position paper.

OECD. 2010. Agricultural Policies in OECD Countries Monitoring and Evaluation. Glossary of Agricultural Policy Terms. Research Laboratories Technical Note 11/2007. OECD.

Soltaninejad K, Faryadi M, Sardari F. 2007. Acute poisoning related deaths in Tehran during the period 2003-2004. J. Forensic Leg. Med., 14: 352-354.

Tirado R. 2007. Nitrates in drinking water in the Philippines and Thailand. Greenpeace Research Laboratories (Technical Note 10/2007). Devon, UK: University of Exeter. (GRL-TN-10-2007), 2-20.

Todd B, Kirama SL, Selejio O. 2012. The supply of inorganic fertilizers to small holder farmers in Tanzania. Evidence for fertilizer policy development" Review version, 6 September 2011. Research report produced by the Kampala office of the International Food Policy Research Institute (IFPRI). Sustainable solutions for ending hunger and poverty. Retrieved from http://www.ifpri.org/sites/default/ files/publications/ifpridp01230.pdf (2013, June 13).

US, EPA. 2007. Sources of common contaminants and their health effects. US, EPA.

US, EPA. 2001. Source Water Protection Practices Bulletin: Managing SmallScale Application of Pesticides to Prevent Contamination of Drinking Water. Office of Water, US, EPA: Washington, DC.

Vijgen J, Abhilash PC, Li Y, Lal R, Forter M, Torres J, Singh N, Yunus M, Tian C, Schäffer A, Weber R. 2011. Hexachlorocyclohexane $(\mathrm{HCH})$ as new Stockholm Convention POPs - a global perspective on the management of Lindane and its waste isomers. Environmental Science and Pollution Research, 18(2): 152-162.

Weiss JM, Bauer O, Blüthgen A, Ludwig AK, Vollersen E, Kaisi M. 2006. Distribution of persistent organochlorine contaminants in infertile patients from Tanzania and Germany. J. Assist. Reprod. Genet., 23: 393-399.

World Bank. 2012. Agribusiness Indicators. World Bank: Tanzania; 73.

Zhu ZL, Chen DL. 2002. Nitrogen fertilizer use in China. Nitrogen fertilizer use in China - Contributions to food production, impacts on the environment and best management strategies. Nutrient Cycling in Agro-Ecosystems, 63(2-3): 117-127. 